\title{
PENGEMBANGAN LEMBAR KERJA PESERTA DIDIK (LKPD) BERBASIS PEMBELAJARAN KOOPERATIF TIPE JIGSAW PADA MATERI LAPISAN BUMI KELAS VII
}

\author{
Ahmad Ghulam Bahrudin ${ }^{1}$ \\ Nur Kuswanti ${ }^{2}$ \\ Andri Wahyu Wijayadi ${ }^{3}$ \\ Universitas Hasyim Asy'ari ${ }^{1,2}$ \\ Universitas Negeri Surabaya ${ }^{2}$
}

\author{
INFO ARTIKEL \\ Diterima: $19-12-2020$ \\ Disetujui: 3-2-2021
}

Kata Kunci:

Pengembangan, LKPD, ADDIE, Jigsaw

\begin{abstract}
Abstrak: Latar belakang penelitian ini berdasarkan penyebaran angket kepada peserta didik di SMP N 1 Ngoro yang menunjukkan bahwa buku masih menjadi sumber belajar utama. Pembelajaran konvensional masih mendominasi proses pembelajaran di kelas. Materi Lapisan Bumi dianggap sulit oleh peserta didik karena banyak istilah asing yang harus dihafal oleh peserta didik. Penelitian ini bertujuan untuk mendeskripsikan proses pengembangan LKPD berbasis pembelajaran kooperatif tipe jigsaw pada materi Lapisan Bumi kelas VII berdasarkan prosedur pengembangan ADDIE. Penelitian ini juga bertujuan mendeskripsikan Validitas LKPD berbasis pembelajaran kooperatif tipe jigsaw pada materi Lapisan Bumi kelass VII yang dikembangkan. Penelitian ini termasuk jenis penelitian pengembangan yang menggunakan model pengembangan ADDIE yang dikembangkan oleh Dick and Carrey. Model pengembangan ini memiliki lima tahapan yaitu, 1) analize, 2) design, 3) develop 4) implementation, 5 ) evaluate. Validitas LKPD didapatkan setelah draft LKPD yang telah direviu oleh dosen pembimbing di validasi ke dua dosen IPA dan satu guru SMP. Penelitian ini menghasilkan LKPD IPA berbasis pembelajaran kooperatif tipe jigsaw pada materi Lapisan Bumi. Berdasarkan hasil validasi oleh 3 validator (2 dosen IPA dan 1 guru IPA) diperoleh hasil validasi sebesar 3,57 dan dikategorikan sangat valid untuk LKPD materi Lapisan Bumi untuk kelas VII.
\end{abstract}

\begin{abstract}
:
The background of this research is based on distributing questionnaires to students at SMP N 1 Ngoro which shows that books are still the main learning resource. Conventional learning still dominates the learning process in the classroom. The material of the Earth's layers is considered difficult by students because there are many foreign terms that students have to memorize. This study aims to describe the process of developing LKPD based on the type of jigsaw cooperative learning on the Earth Layer material for class VII based on the ADDIE development procedure. This study also aims to describe the validity of the LKPD based on the jigsaw cooperative learning type on the material of the Class VII Earth Layer which was developed. This research is a type of development research that uses the ADDIE development model developed by Dick and Carrey. This development model has five stages, namely, 1) analyze, 2) design, 3) develop 4) implementation, 5) evaluate. The validity of the LKPD was
\end{abstract}


obtained after the LKPD draft that had been reviewed by the supervisor was validated by two science lecturers and one junior high school teacher. This research produces LKPD IPA based on jigsaw cooperative learning on the Earth Layer material. Based on the results of the validation by 3 validators $(2$ science lecturers and 1 science teacher), the validation results were 3.57 and were categorized as very valid for the Earth Layer material LKPD for class VII.

\author{
Alamat Korespondensi:

Nama : Ahmad Ghulam Bahrudin ${ }^{1}$ \\ Instansil : Universitas Hasyim Asy'ari \\ Alamat instansi : Tebuireng, Jl. Irian Jaya No.55, Cukir, Kec. Diwek, Kabupaten Jombang, \\ Jawa Timur 61471 \\ e-mail : : udinhulam@gmail.com ${ }^{1}$ \\ Nama : Nur Kuswanti ${ }^{2}$ \\ Instansil : Universitas Negeri Surabaya ${ }^{2}$ \\ Alamat instansi : Jl. Lidah Wetan, Lidah Wetan, Kec. Lakarsantri, Kota SBY, Jawa Timur \\ 60213 \\ e-mail $\quad$ : nurkuswanti@unesa.ac.id ${ }^{2}$ \\ Nama : Andri Wahyu Wijayadi ${ }^{3}$ \\ Instansil : Universitas Hasyim Asyári ${ }^{3}$ \\ Alamat instansi : Tebuireng, Jl. Irian Jaya No.55, Cukir, Kec. Diwek, Kabupaten Jombang, \\ Jawa Timur 61471 \\ Email $\quad$ : diaandri@gmail.com ${ }^{3}$
}

Menurut Undang-Undang Republik Indonesia nomor 20 tahun 2003 tentang sistem pendidikan nasional bahwa pendidikan berdasarkan Pancasila dan Undang-Undang Dasar Negara Republik Indonesia tahun 1945, berfungsi mengembangkan kemampuan dan membentuk watak serta peradaban bangsa yang bermartabat dalam rangka mencerdaskan kehidupan bangsa, bertujuan untuk mengembangkan potensi peserta didik agar menjadi manusia yang beriman dan bertakwa kepada Tuhan Yang Maha Esa, berakhlak mulia, sehat, berillmu, cakap, kreatif, mandiri, dan menjadi warga negara yang demokratis serta bertanggung jawab. Peraturan pemerintah memberikan arahan tentang perlunya disusun dan dilakanakan delapan standar nasional pendidikan, yaitu: satndar isi, standar proses, standar kompetensi lulusan, standar pendidik dan tenaga kependidikan, standar sarana dan prasarana, standar pengelolaan, standar pembiayaan, dan standar penilaian pendidikan. Dalam mewujudkan tujuan nasional tersebut telah ditentukan standar kompetensi lulusan yang merupakan kriteria mengenai kualifikasi kemampuan lulusan yang mencakup sikap, pengetahuan, dan keterampilan. Untuk mencapai kompetensi lulusan tersebut perlu ditetapkan sandar isi yang merupakan kriteria ruang lingkup materi dan tingkat kompetensi peserta didik untuk mencapai kompetensi kelulusan pada jenjang dan jenis pendidikan tertentu. Hal di atas bisa dijadikan sebagai pertimbangan oleh pendidik dalam menentukan model pebelajaran yang sesuai dengan keadaan peserta didik dan materi yang akan diajarnya.

Menurut Kemp dalam Rusman (2012:132) model pembelajaran merupakan suatu kegiatan pembelajaran yang harus dikerjakan oleh pendidik dan peserta didik agar tujuan pembelajaran dapat dicapai secara efektif dan efisien. Model pembelajaran adalah suatu rencana atau pola yang dapat digunakan untuk membentuk kurikulum (rencana pembelajaran jangka panjang), merancang bahan-bahan pembelajaran dam membimbing pembelajaran di kelas atau yang lain (Joyce dan Weil dalam Rusman, 2012:213). Model pembelajaran dapat dijadikan pilihan untuk pendidik untuk melaksanakan pembelajaran yang sesuai dan efisien untuk mencapai tujuan pembelajaranya. 
Berdasarkan penyebaraan angket kepada peserta didik kelas VII tentang pembelajaran mata pelajara IPA SMP Negeri 1 Ngoro yang dilakukan pada tanggal 20 September 2019 didapati masalah yang sering muncul dalam pembelajaran IPA yaitu peserta didik menyukai metode pembelajaran diskusi atau berkelompok dengan persentase $75 \%$ peserta didik menyukai metode tersebut, namun menurut peserta didik $78 \%$ pembelajaran di kelas masih menggunakan metode konvensional. Menurut Herman (2017) metode konvensional mempunyai ciri-ciri pembelajaran berpusat pada pendidik, pendidik menjelaskan materi pelajaran melalui metode ceramah, peserta didik pasif, pertanyaaan dari peserta didik jarang muncul, berorientasi pada satu jawaban yang benar, aktivitas kelas yang sering terjadi hanyalah menyalin atau mencatat. Metode konvensional menyebabkan peserta didik kurang bisa mengembangkan kemampuan pemecahan masalah, penalaran, hubungan dan komunikasi antar peserta didik maupun antara peserta didik dan pendidik.

Berdasarkan hasil wawancara dengan pendidik mata pelajaran IPA kelas VII ditemukan masalah dalam pembelajaran IPA sebagai berikut : Materi yang sulit dipahami oleh peserta didik adalah materi Lapisan Bumi. Kesulitan tersebut disebabkan karena banyaknya istilah asing yang harus dihafalkan oleh peserta didik. Salah satu upaya untuk mengatasi masalah di atas adalah dengan menggunakan model pembelajaran kooperatif tipe jigsaw. Model pembelajaran kooperatif membuat peserta didik berdiskusi dengan teman sebayanya sehingga sesuai dengan model pembelajaran yang disukai oleh peserta didik di kelas. Model pembelajaran kooperatif tipe jigsaw mempunyai sintak membaca, diskusi kelompok ahli, laporan tim, tes dan rekognisi tim. Model tersebut memberikan dua sampai tiga kali pengulangan untuk setiap materi yang dipelajari oleh peserta didik sehingga sesuai dengan permasalahan banyaknya istilah asing yang harus dihafalkan oleh peserta didik.

Model pembelajaran kooperatif memberikan kesempatan kepada siswa untuk bekerjasama dalam menyelesaikan tugas-tugas yang telah ditentukan (Surahmad dalam Abdullah, 2017). Model pembelajaran kooperatif menekankan peserta didik untuk berinteraksi antara peserta didik agar bisa saling berbagi informasi dan pengetahuan yang dimiliki. Model pembelajaran kooperatif berkaitan dengan hal-hal yang menyebabkan anggota kelompok bekerjasama dalam menyelesaikan tugas kelompok. Model pembelajaran kooperatif efektif digunakan karena siswa tidak hanya menerima informasi dari guru tetapi juga memperoleh informasi akibat adanya interaksi siswa di dalam kegiatan kelompok maupun di luar kelompok. Model pembelajaran kooperatif mempunyai banyak tipe salah satunya adalah tipe jigsaw.

Pembelajaran tipe jigsaw merupakan salah satu macam model pembelajaran kooperatif. Model pembelajaran tipe jigsaw membagi siswa ke dalam kelompok-kelompok heterogen yang masing-masing anggota bertanggungjawab untuk mempelajari topik yang ditugaskan dan mengajarkan kepada anggota kelompoknya, sehingga mereka dapat berinteraksi dan saling bantu. Pembelajaran kooperatif tipe jigsaw sesuai apabila diterapkan pada materi-materi yang tidak banyak mengandung rumus atau persamaan namun lebih banyak memuat teori-teori (Hertiavi dkk., 2010). Materi-materi yang demikian memudahkan peserta didik untuk membaca sendiri sebelum pembelajaran dimulai. Hal ini sesuai dengan prinsip pembelajaran kooperatif tipe jigsaw yang mengedepankan pengalaman siswa dan pada pelaksanaannya siswa harus berbagi pengalaman atau pendapat kepada siswa lain. Pembelajaran kooperatf tipe jigsaw tepat digunakan untuk materi Lapisan Bumi karena materi Lapisan Bumi bisa terbagi menjadi beberapa bagian yang mempunyai tingkat kesulitan sama.

Menurut Jhonson dan Jhonson (2002) dalam Rusman (2012:219) model pembelajaran kooperatif tipe jigsaw menunjukkan bahwa interaksi kooperatif memiliki berbagai pengaruh positif terhadap perkembangan anak. Pengaruh positif tersebut adalah : 1) Meningkatkan hasil belajar. Berdasarkan analisa hasil angket dan wawancara di atas salah satu alasan hasil belajar rendah adalah bentuk pembelajaran di kelas yang masih berpusat pada guru. 2) Meningkatkan daya ingat, dalam pembelajaran kooperatif tipe jigsaw peserta didik mengalami pengulangan materi sebanyak tiga kali. Dengan demikian penerapan model pembelajaran kooperatif tipe jigsaw meningkatkan daya ingat peserta didik terhadap materi yang telah diajarkan.

Menurut Slavin (2005) langkah-langkah pembelajaran kooperatif tipe jigsaw meliputi: 1) Membaca, peserta didik dibagi menjadi kelompok heterogen dan menerim topik ahli untuk 
selanjutnya dibaca. 2) Diskusi kelompok ahli, Peserta didik yang menerima topik sama bergabung membentuk kelompok baru yang disebut sebagai kelompok ahli. 3) Laporan tim, para ahli kembali ke kelompok asalnya untuk mengajari topik yang mereka kuasai ke teman kelompok asalnya. 4) Tes, peserta didik mengerjakan kuis individual yang mencakup semua topik. 5) Rekognisi tim, penghitungan skor tim berdasarkan kuis yang telah dikerjakannya.

Materi lapisan bumi terletak pada KD 3.10 Menjelaskan lapisan bumi, gunung api, gempa bumi, tindakan pengurangan resiko sebelum, pada saat, dan pasca bencana sesuai ancaman bencana di daerahnya. KD 3.10 terdiri atas materi atmosfer, litosfer, dan hidrosfer. Setiap topik memiliki banyak istilah baru bagi peserta didik sehingga menyulitkan peserta didik untuk memahami materi tersebut. Materi Lapisan Bumi mempunyai materi yang luas dan tidak berkaitan antar materi satu dengan materi yang lainnya. Materi lapisan bumi sulit dipahami peserta didik disebabkan oleh peserta didik kurang mampu konsep pembelajaran karena malas membaca materi yang ada di buku teks (Sari,dkk.,2018). Berdasarkan alasan-alasan diatas maka materi lapisan materi-bumi termasuk materi yang sulit dipahami oleh peserta didik dan berimbas pada hasil belajar peserta didik.

Selain itu, berdasarkan penyebaran angket diketahui bahwa peserta didik lebih mudah memahami suatu materi pelajaran yang memuat tulisan dan gambar. Kondisi di kelas saat pembelajaran masih menggunakan buku sebagai sumber belajar utama sedangkan internet dan koran atau majalah sebagai sumber belajar pendukung. Sehingga peserta didik tidak mempunyai pilihan lain selain menjadikan buku sebagai sumber belajar utamanya.

Saat proses pembelajaran pendidik membutuhkan bahan ajar untuk menunjang keberhasilan pembelajarannya. Bahan ajar merupakan segala bahan (informasi, alat, dan teks) yang disusun secara sistematis, yang digunakan pendidik dan peserta didik dalam proses pembelajaran (Pannen dalam Prastowo 2015:17). Misalnya, modul, LKS, Handout, dan model atau maket.

Menurut Prastowo 2015:204 LKS merupakan suatu bahan ajar cetak berupa lembaranlembaran kertas berisi materi, ringkasan, dan petunjuk-petunjuk pelaksanaan tugas pembelajaran yang harus dikerjakan oleh peserta didik, yang mengacu pada kompetensi dasar yang harus dicapai. Tugas-tugas yang diberikan kepada peserta didik dapat berupa tugas teoritis maupun tugas praktis. Tugas teoritis misalnya berupa membaca buku atau artikel, membuat resume untuk dipresentasikan didepan kelas. Adapun tugas praktis dapat berupa kerja laboratorium dan kerja lapangan.

Saleh dkk (2017) mengembangkan LKPD berbasis pembelajaran kooperatif tipe jigsaw pada materi konsep larutan dengan menggunakan model pengembangan 4-D. Berdasarkan hasil penelitian tersebut diperoleh hasil kevalidan LKPD sebesar 3,50 (berada pada kategori sangat valid), kepraktisan LKPD sebesar 3,81 (teralaksana seluruhnya), dan keefektifannya yang diukur dengan hasil belajar menunjukan angka $100 \%$ peserta didik memperoleh nilai diatas KKM.

LKPD berbasis pembelajaran kooperatif tipe jigsaw ini memuat materi Lapisan Bumi menggunakan model pengembangan ADDIE (analyze, design, development, implementation, evaluate). Model ini dipilih berdasarkan pertimbangan bahwa model pengembangan ini bersifar sistematis dan pijakannya mengacu pada landasan pembelajaran yang teoritis (Tegeh, 2014: 78). Berdasarkan uraian masalah di atas maka dilakukan penelitian yang berjudul Pengembangan LKPD Berbasis Pembelajaran Kooperatif Tipe Jigsaw pada Materi Lapisan Bumi Kelas VII.

\section{METODE}

Penelitian ini menggunakan model pengembangan ADDIE yang dikembangkan oleh Dick and Carrey (Tegeh, 2014: 41). Model pengembangan ADDIE terdiri atas lima tahapan yaitu: 1) Analyze (analisa) 2) Design (desain/perancangan) 3) Development (pengembangan) 4) Implementation (implementasi) Tidak dapat dilakukan karena pandemi covid-19 5) Evaluation (evaluasi).

Data yang diperoleh dari pengembangan Lembar Kerja Peserta Didik (LKPD) berbasis pembelajaran kooperatif tipe jigsaw ini adalah data kuantitatif dan kualitatif. Data kuantitatif dan kualitatif ini mendiskripsikan tentang proses pengembangan LKPD berbasis pembelajaran 
kooperatif tipe jigsaw. Data diperoleh dari masukan dosen pembimbing, guru SMP/MTs, dan dosen ahli produk. Serta, kevalidan LKPD berbasis pembelajaran kooperatif tipe jigsaw. Perolehan data diambil dari hasil penilaian oleh dosen ahli LKPD, dosen ahli materi, dan guru IPA.

\section{HASIL DAN PEMBAHASAN}

Tahapan analisis diakukan pada bulan September 2019 dimulai dengan menganalisis kurikulum dan materi melalui observasi dan wawancara dengan guru IPA di SMP Negeri 1 Ngoro. Pada tahap ini diketahui bahwa kurikulum yang digunakan SMP Negeri 1 Ngoro yakni Kurikulum 2013 (K13). Sedangkan analisis materi guru SMP Negeri 1 Ngoro mengemukakan bahwa salah satu materi yang dirasa sulit oleh peserta didik adalah materi Lapisan Bumi. Materi Lapisan Bumi meliputi lapisan-lapisan penyusun bumi yaitu, lapisan litosfer, lapisan atmosfer dan lapisan hidrosfer. Berdasarkan hal tersebut peneliti memilih materi Lapisan Bumi untuk dikembangkan perangkat medianya yaitu LKPD IPA berbasis pembelajaran kooperatif tipe jigsaw. Pengembangan LKPD IPA berbasis pembelajaran kooperatif tipe jigsaw disesuaikan dengan kurikulum yang dipakai di SMP Negeri 1 Ngoro yang meliputi Kompetensi Inti (KI) 3. Memahami pengetahuan (factual, konseptual, dan procedural) berdasarkan rasa ingin tahunya tentang ilmu pengetahuan, teknologi, seni, budaya terkait fenomena tampak mata. Kompetensi Dasar (KD) dan indikator pembelajaran dapat dilihat pada tabel berikut.

Tabel 1 Kompetensi Dasar dan Indikator Pembelajaran Materi Lapisan Bumi

\section{Kompetensi Dasar Indikator Pembelajaran}

3.10 Menjelaskan lapisan bumi, gunung 3.10.1 Menjelaskan karakteristik lapisan penyusun bumi. api, dan tindakan pengurangan 3.10 .2 Menjelaskan karakteristik lapisan atmosfer. resiko sebelum, pada saat, dan 3.10 .3 Menjelaskan teori tentang pergerakan benua. pasca bencana sesuai ancaman 3.10 .4 Menjelaskan teori tentang seafloor spreading. bencana di daerahnya

3.10.5 Menjelaskan teori tentang tektonik lempeng. 3.10.6 Menjelaskan Siklus hidrologi.

Tabel diatas menunjukkan bahwa kompetensi dasar (KD) 3.10 dibagi menjadi bebearapa indikator pembelajaran yang meliputi 1) Menjelaskan karakterisktik lapisan penyusun bumi. 2) Menjelaskan karakteristik lapisan atmosfer. 3) Menjelaskan teori tentang pergerakan benua. 4) Menjelaskan teori tentang seafloor spreading. 5) Menjelaskan teori tentang tektonik lempeng. 6) Menjelaskan siklus hidrologi.

Setelah memperoleh hasil analisis kurikulum kemudian dilakukan analisis peserta didik. Hasil analisis peserta didik dapat dilihat berdasarkan hasil dari rekapitulasi angket observasi peserta didik dan wawancara dengan guru IPA yang mengajar di kelas eksperimen pada Tabel berikut:

Tabel 2 Hasil Rekapitulasi Angket Observasi peserta didik dan wawancara dengan guru IPA

\begin{tabular}{lll}
\hline No & \multicolumn{1}{c}{ Indikator } & \multicolumn{1}{c}{ Kesimpulan } \\
\hline 1 & $\begin{array}{l}\text { Kegiatan pembelajaran yang sering } \\
\text { digunakan guru IPA }\end{array}$ & $\begin{array}{l}\text { Sebanyak 78,1\% guru menggunakan pembelajaran } \\
\text { dengan menjelaskan didepan kelas. }\end{array}$ \\
\hline 2 & Materi IPA yang dianggap sulit & $\begin{array}{l}\text { Materi yang sulit dipahami oleh peserta didik adalah } \\
\text { materi Lapisan Bumi karena banyaknya istilah asing } \\
\text { yang harus dihafalkan oleh peserta didik }\end{array}$ \\
\hline 3 & $\begin{array}{l}\text { Media/alat bantu belajar yang sering } \\
\text { digunakan guru dalam pembelajaran }\end{array}$ & $\begin{array}{l}\text { Sebanyak 93,8\%\% guru menggunakan media papan } \\
\text { tulis. }\end{array}$ \\
\hline 4 & $\begin{array}{l}\text { Hal yang mempermudah peserta } \\
\text { didik dalam memahami materi }\end{array}$ & $\begin{array}{l}\text { Sebanyak 59,4\% peserta didik lebih mudah memahami } \\
\text { materi dalam bentuk gambar dan tulisan. }\end{array}$ \\
\hline 5 & $\begin{array}{l}\text { Kegiatan pembelajaran yang disukai } \\
\text { peserta didik }\end{array}$ & $\begin{array}{l}\text { Sebanyak 78,1\% peserta didik menyukai kegiatan } \\
\text { pembelajaran berkelompok. }\end{array}$ \\
\hline
\end{tabular}

Tabel diatas menunjukkan bahwa 78,1\% guru menggunakan pembelajaran didepan kelas. Materi yang sulit dipahami oleh peserta didik adalah materi Lapisan Bumi karena materi 
Lapisan Bumi banyak memuat istilah asing yang harus dihafalkan oleh peserta didik. Media/alat bantu belajar yang digunakan oleh guru dalam pembelajaran adalah papan tulis. Peserta didik lebih mudah memahami materi pelajaran dalam bentuk tulisan dan gambar. Kegiatan pembelajaran yang disukai oleh peserat didik adalah pembelajaran berkelompok. Dari adanya data tersebut diketahui bahwa LKPD IPA berbasis pembelajaran kooperatif tipe jigsaw materi Lapisan Bumi dapat efektif digunakan dalam pembelajaran IPA.

Tahapan awal perancangan LKPD IPA berbasis pembelajaran kooperatif tipe jigsaw materi Lapisan Bumi dilakuka pada bulan Oktober 2019 sampai bulan maret 2020. Perancangan dimulai dengan mengumpulkan referensi materi Lapisan Bumi pada buku paket kelas VII tingkat SMP/MTs. Selanjutnya mengumpulkan referensi LKPD IPA yang baik untuk membuat desain LKPD IPA yang sesuai dengan karakteristik peserta didik. Menyusunan naskah materi Lapisan Bumi secara keseluruhan sesuai dengan indikator dan tujuan pembelajaran serta memilih tampilan LKPD IPA berbasis pembelajaran kooperatif tipe jigsaw yang dikembangkan oleh peneliti. Menentukan bentuk LKPD dan metode evaluasi.

Tahapan pengembangan menghasilkan 2 draft LKPD IPA berbasis pembelajaran kooperatif tipe jigsaw yang dideskripsikan sebagai berikut: Pengembangan LKPD dilakukan pada bulan April 2020 sampai Juni 2020. LKPD IPA berbasis pembelajaran kooperatif tipe jigsaw berisi materi pembelajaran yang disesuaikan dengan tujuan pembelajaran serta dilengkapi petunjuk penggunaan LKPD untuk membantu peserta didik dalam melakukan kegiatan pembelajaran dalam LKPD. Selain tahap pengembangan tersebut dilakukan juga tahap desain pada isi LKPD IPA berbasis pembelajaran kooperatif tipe jigsaw menggunakan ms. Word yang dilakukan dengan memberi efek warna, shape, dan picture agar lebih menarik untuk peserta didik. Hasil dari pengembangan ini berupa LKPD IPA berbasis pembelajaran kooperatif tipe jigsaw yang selanjutnya diekspor menjadi draft Lembar Kegiatan untuk peserta didik.

Setelah tahap editing selesai maka diperoleh draft 1 LKPD IPA berbasis pembelajaran kooperatif tipe jigsaw. Draft I LKPD ini mendapat masukan dan saran dari dosen pembimbing. saran dan masukan dari dosen pembimbing, yaitu: 1) Model pembelajaran belum tercantum pada cover LKPD, 2) Identitas penyusun LKPD belum tercantum pada cover LKPD 3) Memisahkan nama penyusun dengan identitas prodi, fakultas dan kampus serta membesarkan dan menebalkan fontnya, 4) Judul LKPD kurang menarik. Font LKPD kurang besar. Jarak antar poin tidak sama. Mengganti kalimat 'petunjuk pemakaian' dengan kalimat 'petunjuk umum'. Poin-poin pada petunjuk umum kurang rapi. Kata 'kelompok' kurang jelas antara 'kelompok asal dan kelompok ahli'. Terdapat kesalahan penulisan pada kata 'nomer', 5) Bagian 'membaca' kurang menarik. Ada penomoran yang dobel. Uraian terlalu panjang. Ada kalimat perintah yang dobel. Menghapus kalimat 'sebelum mengerjakan soal dibawahnya'. Tidak menyebutkan teoriteori yang akan dipelajari. Mengahapus penomoran pada kalimat 'teori pergerakan bumi', 6) Bagian 'diskusi kelompok ahli' kurang menarik. Mengganti kata 'soal' menjadi 'pertanyaan'. Menambahkan kalimat 'kelompok ahli', 7) Bagian 'laporan tim', 'tes', 'rekognisi tim' kurang menarik. Tidak perlu mencantumkan soal yang akan dibacakan oleh guru. Kurang kalimat 'dan mendiskusikan teori lain tentang litosfer'. Mengganti kata 'soal' menjadi 'pertanyaan'. Merevisi kata 'jumlahkan', 8) Gambar dengan keterangan terpisah halaman, 9) LKPD kurang rapi dan gambar terpisah dengan keterangan gambarnya, 10) Pisahkan judul LKPD ke halaman selanjutnya, 11) Gambar tidak memiliki keterangan gambar, 12) Gambar dan instruksi tidak boleh terpisah.

Setelah LKPD direvisi sesuai saran dan masukan dosen pembimbing, kemudian diakukan revisi secara keseluruhan dan menghasilkan draft II LKPD IPA berbasis pembelajaran kooperatif tipe jigsaw. Draft II LKPD yang telah disetujui dosen pembimbing dan divalidasi oleh dosen ahli materi, ahli media dan guru IPA. Berikut adalah hasil validasi LKPD IPA berbasis pembelajaran kooperatif tipe jigsaw.

Tahapan Evaluasi diperoleh data berupa hasil validasi LKPD IPA berbasis pembelajaran kooperatif tipe jigsaw dari ahli media, materi dan guru IPA. Hasil penilaian dari validator terhadap kelayakan LKPD IPA berbasis pembelajaran kooperatif tipe jigsaw yang dikembangkan oleh peneliti, mendapat rata-rata 3,57 dengan kategori sangat valid.

\section{SIMPULAN}


KARANGAN: Jurnal Kependidikan, Pembelajaran, dan Pengembangan, Vol 03, No 01, Bulan Februari, Tahun 2021, Hal 36-43

Proses pengembangan LKPD berbasis pembelajaran kooperatif tipe jigsaw ini menggunakan model pengembangan ADDIE. Model pengembangan ADDIE mempunyai 5 tahapan yaitu,1) Tahap analisis, pada tahap ini dilakukan analisis kurikulum, analisis materi, dan analisis peserta didik yang diperlukan untuk mengembangkan LKPD. 2) Tahap desain, Pada tahap ini peneliti menyusun LKPD berbasis pembelajaran kooperatif tipe jigsaw pada materi Lapisan Bumi. 3) Tahap pengembangan, pada tahap ini LKPD yang telah disusun disetorkan kepada dosen pembimbing untuk mendapatkan masukan. 4) Tahap Implementasi, pada tahap ini tidak dapat dilaksanakan karena sedang terjadi pandemi covid-19 yang menyebabkan pembelajaran di sekolah dilakukan secara online (daring). 5) Tahap evaluasi, evaluasi dilakukan pada setiap tahapan berdasarkan masukan dari dosen pembimbing dan validator.

Berdasarkan hasil validasi oleh validator (2 dosen IPA dan 1 Guru IPA) didapatkan hasil validasi sebesar 3,57 dan dikategorikan sangat valid sebagai LKPD pada materi Lapisan Bumi, sehingga layak digunakan dalam pembelajaran karena memnuhi syarat didaktik, syarat konstruksi dan syarat teknis.

\section{DAFTAR RUJUKAN}

Abdullah,Ramli. Pengaruh Model Pembelajaran Kooperaatif Tipe Jigsaw Pada Mata Pelajaran Kimia Di Madrasah Aliyah.Lantanida Journal,Vol. 5 No 12017

Batoq dkk.2015.Pengembangan Perangkat Pembelajaran Model Kooperatif Tipe Jigsaw Berbasis Kurikulum 2013 Pada Materi Pelajaran Sistem Pendinginan Bahan Bakar dan pelumas di SMKN 3 Sendawar.Jurnal Pendidikan Vokasi:Teori dan Praktek ISSN: 2302$285 \mathrm{x}$.

Budiawan Made dan Arsani Ni Luh Kadek Alit. 2013. Pengaruh Model Pembelaharan Kooperatif tipe jigsaw dan Motivasi Belajar terhadap Prestasi Belajar Ilmu Fisiologi Olaharaga. Jurnal Pendidikan Indonesia Vol 2 No. 1 April 2013

Herawati, lidia dan Irwandi.2019. Pengaruh Model Pembelajaran Kooperatif Tipe Jigsaw Terhadap Hasil Belajar dan Berpikir Kritis Siswa Pada Mata Pelajaran IPA di SMP negeri 09 Lebong. ISBN 978-602-99975-3-8.

Herman, Dwi Surjono, 2017. Multimedia Pembelajaran Interaktif. Yogyakarta: UNY Press

Hertiavi dkk.2010.Penerapan Model Pembelajaran Kooperatif Tipe Jigsaw Untuk Peningkaatkan Kemampuan Pemecahan Masalah Siswa SMP.Jurnal Pendidikan Fisika Indonesia 6 (2010) 53-57.

Insany, Yeni Agustine Shovia.2016 Pengaruh Model Pembelajaran Kooperatif Tipe Jigsaw Terhadap Hasil Belajar Siswa pada Pelajaran Fisika SMK. Jurnal Pemikiran Penelitian pendidikan dan Budaya Vol. 4, No.1, Juni 2016.

Irham,dkk.2017. Pengaruh Model Pembelajaran Kooperatif Tipe Jigsaw Terhadap Motivasi Belajar dan Hasil Belajar Biologi Siswa Kelas XI IPA SMP Negeri 18 Bulukumba. Vol.1, No 1, November 2017 e-ISSN: 2581-1967s p-ISSN: 2581-1959

Mahmudah dkk.2017. Analisis Kebutuhan Multimedia Interaktif Science Edutainment pada Tema Bumi untuk Siswa SMP. Universitas Negeri Malang 7 Oktober 2017

Nurdyansyah dan Fitriyani Toyiba . 2016. Pengaruh Startegi Pembelajaran Aktif Terhadap Hasil Belajar Madrasah Ibtidaiyah. Jurnal TEKPEN, Jilid 1, Terbitan 2, 929-930.

Prastowo,Andi.2014.Pengembangan Bahan Ajar Tematik.Jakarta:Kencana.

Prastowo,Andi.2015.Panduan Kreatif Membuat Bahan Ajar Inovatif.Jogjakarta:Diva Pres.

Pribadi,Beni dan Dewi Padmo putri.Pengembangan Bahan Ajar.Banten:Universsitas Terbuka.

Rahmi, Ennike Gusti.2017. Pengaruh Model Pembelajaran Kooperatif Tipe Jigsaw dan Kemampuan Awal Siswa Terhadap Hasil Belajar Biologi Siswa Kelas XI IPA SMAN 1 Bonjol. ISSN 2527-6018 e-ISSN 2548-4141.

Rusman.2012.Model-model Pembelajaran Mengembangkan Profesionalisme Guru.Depok:RajaGrafindo Persada.

Saleh dkk.2017.Pengembangan Perangkat pembelajaran Kooperatif Tipe Jigsaw Pada Materi Konsep Larutan di SMK Negeri 3 Batang. Chemistry Education Review. Pendidikan Kimia PPs UNM 2017 Vol 1 No 1 (56-57). 
KARANGAN: Jurnal Kependidikan, Pembelajaran, dan Pengembangan, Vol 03, No 01, Bulan Februari, Tahun 2021, Hal 36-43

Sari Eci Verwita,dkk.2018. Pengaruh Pemberian Spelling Puzzle dengan Model Problem Based Learning Terhadap Pencapaian Kompetensi Siswa IPA Kelas VII Materi Pemanasan Global dan Lapisan Bumi SMP Negeri 12 Padang. Pillar of physics Education, Vol 11 No 3, 2018, 9-16.

Sari,dkk. 2017. Batasan Prasyarat Uji Normalitas dan Uji Homogenitas Pada Model Regresi Linear. Universitas Negeri Semarang ISSN 2252-6943.

Septiyani, Aninda Wulan dkk. Pengaruh Model Pembelajaran Kooperatif Tipe Jigsaw Terhadap Peningkatan Keterampilan Sosial dan Hasil Belajar.

Slavin,Robert E.2005. Coopeartive Learning.Bandung:Nusa Media.(Penerjemah Nuralita Yusron).

Sugiyono.2015. Metode Penelitian Pendidikan. Bandung:Alfabeta.

Sukmawati, Mega. 2019.Pengembangan Media Pembelajaran Menggunakan Software Prezi pada Materi Atom, Molekul, dan Ion Kelas VIII untuk SMP.Skripsi Universitas Hasyim Asy'ari Tebuireng:Jombang.

Sumarsih.2017.Upaya Peningkatan Motivasi dan Prestasi Belajar IPA Melalui Penerapan Model Pembelajaran Jigsaw pada Siswa Kelas IX B SMP Negeri 9 Yogyakarta.Jurnal Penelitian dan Evaluasi Pendidikan Volume V Nomor 2 November 2017.

Supriyono,Agus.2014. Coopeartive learning Teori dan Aplikasi Paikem.Yogyakarta:Pustaka Pelajar.

Tegeh, Made dkk.2014. Model Penelitian Pengembangan. Yogyakarta:Graha Ilmu.

Widodo,Wahono dkk.2017. Ilmu Pengrahuan Alam SMP/MTs Kelas VII Semester 2.Jakarta:Pusat Kurikulum dan Perbukuan, Balitbang, Kemendikbud. 